\title{
UPAYA GURU MENINGKATKAN BUDAYA LITERASI MINAT BACA "OPEN READING GARDEN" SISWA KELAS IVA DI SEKOLAH ADIWIYATA SD NEGERI KEMIRIREJO 1 MAGELANG
}

Stevani Silvia Sulistianing Wiranti

Pustakawan SD Negeri Kemirirejo 1 Magelang

email : Silviastefany026@gmail.com

\section{Abstrak}

Tujuan penelitian ini untuk mendiskripsikan hal yang dilakukan guru dalam peningkatkan budaya literasi minat baca open reading garden siswa kelas IVA SD Negeri Kemirirejo 1 Magelang. Peneliti menggunakan sistem penelitian kualitatif. Subjek yang diteliti guru kelas IVA dan siswa kelas IVA berjumlah 32 di SD Negeri Kemirirejo 1 Magelang. Pengumpulan datanya menggunakan observasi dan wawancara. Dari hasil ini guru diharapkan mampu untuk : (1) Memotifasi siswa untuk ikut dalam kegiatan mendongeng, (2) Menyarankan untuk memebeli buku sesuai dengan minat, (3) Meluangkan waktu untuk membaca 15 menit sebelum pembelajaran, dengan memberikan motifasi diharapkan siswa lebih termotifasi untuk lebih giat meningkatkan budaya literasi minat baca. Salah satu cara yang dapat guru lakukan dengan meminta untuk berkunjung ke Perpustaaan Gita Pustaka atau ke tempat Open Reading Garden SD Negeri Kemirirejo 1 Magelang untuk meminjam buku yang menjadi minat baca mereka. Minat baca mereka dapat dilihat dari kunjungan mereka ke Perpustakaan Gita Pustaka pada jam pulang sekolah.
Kata Kunci :

Guru, Minat Baca, Siswa

\section{A. PENDAHULUAN}

Informasi menjadi bahan pokok berkembangnya sumber daya manusia. Informasi tidak hanya diperlukan untuk personal saja melainkan hampir seluruh aspek masyarakat baik pelajar maupun pendidik. Sekolah sebagai institusi pendidikan dan sebagai tempat pembelajaran. Pendidikan bisa dilakukan dengan bimbingan orang lain maupun secara alami. Pelajaran dalam segi wawasan dan kemampuan seseorang dapat ditularkan ke generasi generasi berikutnya melalui proses pendidikan. Yang dimaksut proses pendidikan yaitu di mana manusia mampu meningkatkan seluruh potensi dalam dirinya. Melalui kurikulum sekolah yang menjadi acuan untuk seluruh pendidik.

Dalam hal ini perpustakaan ialah suatu ruang ataugedung secara khusus menyediakan buku-buku sebagai bahan informasi ataupun sebagai bahan rujukan dan tidak diperjual belikan. Perpustakaan sekolah sebagai salah satu wadah sekaligus sarana penunjang siswa, menyediakan bermacam-macam informasi sesuai keinginan pengguna. Apalagi dengan berkembangnya era digitalisasi dan jaman milenial sekarang ini. Minat baca peserta didik dari segala aspek sangatlah kurang terutama di dalam instansi pendidikan dasar. Dalam Permendikbud No 23 Tahun 2015 mengenai Penumbuhan Budi Pekerti yaitu dihimbau seluruh pemangku kepentingan pendidikan ikut andil dalam melaksanakan setiap pembiasaan yang terdapat dalam permendikbud No 23 Tahun 2015. Salah satunya adalah gerakan literasi minat baca sekolah.

Sedangkan literasi suatu kegiatan daya serap untuk memperoleh informasi. Gerakan Literasi suatu upaya yang dilakukan pemerintah sehingga memang harus digalakkan dan dilaksanakan secara maksimal. Dari hasil survey Badan Pusat Statistika di bulan Nov 2014, pada Tahun 2006 masyarakat Indonesia hal membaca belum menjadi kebiasaan dalam memperoleh informasi.

Ada banyak factor yang menjadikan Literasi minat baca sekolah dasar berkurang. Dan ini terjadi 
dengan siswa kelas IVA SD Negeri Kemirirejo 1 Magelang. Dari hasil servei pada Tanggal 1-4 Agustus 2018 pada siswa kelas IVA SD Negeri Kemirirejo 1 Magelang mempunyai banyak ragam jenis buku yang dibaca baik buku cerita, komik, majalah, cerita,namun mereka lebih memilih untuk bermain dibandingkan dengan membaca.

Berdasarkan latar belakang di atas penulis dapat menyimpulkan rumusan masalah yaitu Bagaimana cara guru kelas IVA meningkatkan budaya literasi minat baca siswa kelas IVA SD Negeri Kemirirejo 1 Magelang?

Tujuan penelitian ini yaitu untuk mengetahui berbagai upaya yang dilakukan oleh guru kelas IVA dalam rangka meningkatkan budaya literasi serta minat baca siswa kelas IVA SD Negeri Kemrirejo 1 Magelang.

\section{B. KAJIAN TEORITIS}

\section{Peran Guru Sebagai Tenaga Pendidik}

Guru adalah seseorang yang menjadi contoh bagi siswa yang harus memili kulitas yang mampu di gunakan untuk mengajar dan mengambil keputusan tanpa harus menunggu perintah dari kepala sekolah. Hal hal yang dapat dilakukan seperti bertanya, mendengar, memberikan perintah atau pesan kepada semua siswanya. Pendapat Mulyasamenjelaskan guru harus memiliki standart kualitas diri baik tagung jawab, mandiri, wibawa, dan kedisiplinan (Rahim, 2007, p. 37).

\section{Tinjauan Literasi Minat Baca}

Minat yaitu rasa tertarik bada benda atau objek tertentu yang membuat rasa minat itu muncul sehingga bisa menjadi penyebab faktor dalam kegiatan yang berkaitan erat dengan perasaan senang, emosi, kehendak yang mewujudkan rasa kemauan.

Menurut Engking Mudyana Dan Rohani perpustakaan yaitu sarana pendidikan yang menjadi penunjang dalam pendidikan yang bertindak sebagai pelestari bahan pustaka dan sebagai sumber dalam bahan pendidikan yang diwariskan kegenari berikutnya (Sinaga, 2005, p. 16). Menjadi suatu kenyataan bahwa perpustakaan menjadi sarana belajar mengajar bagi siswa dan guru. Selain sebagai proses belajar mengajar perpustakaan juga memiliki tugas lain yaitu sebagai pengelola perpustakaan. Salah satu Rancangan Pendidikan yaitu Pergerakan Budaya Literasi Minat Baca Perpustakaan. Kegiatan ini memiliki tujuan agar mampu mendorong terwujudnya manusia pembelajar sepanjang hayat melalui kegiatan litersai.

\section{Membaca}

Menurut Darmiyati Zuchdi dan Budiasih (1997, p. 49) mengatakan bahwa membaca menjadi satu jenis skil berbahasa tulis yang memiliki sifat reseptif. Karena dengan membaca maka akan mendapatkan suatu informasi yang menjadi unsur penting bagi perkembangan pengetahuan manusia.

\section{Upaya Meningkatkan Minat Baca}

Setiap guru memili trik atau cara agar menjadi motivator bagi siswa atau memiliki kajian untuk mendorong siswa untuk lebih semangat, seperti memberikan tugas rumah atau memiliki indicator kualitas membaca. Hal yang dapat dilakukan dalam meningkatkan minat baca antara lain:

1. Memberi bacaan sejak dini

2. Mendorong siswa untuk mendongeng dari bacaan yang dia baca

3. Membeli buku yang diminati siswa

4. Membuat perpustakaan mini

Dengan demikian kesimpulan yang dapat diambil yaitu kekreatifan orang tua juga dibutuhakan untuk menumbuhkan minat baca anak.

\section{Karakteristik Siswa Sekolah Dasar}

Karakter anak muncul ketika masa pertumbuhan kira kira umur 2 tahun ketika anak mulai berbicara. Dan tahap pengenalan symbol dan bahasa di umur 2-7 tahun.

\section{METODE PENELITIAN}

Metode Penelitian adalah cara bagaimana 
menentukan penelitian tersebut dilakukan. Sedangkan peniliti bisa menggunakan metode penelitian baik metode peneletian kualitatif atau metode kuantitatif. Sedangkan penulis menggunakan metode kualitatif, metode yang digunakan untuk mengkaji suatu objek secara alamiah tanpa ada manipulasi, dan secara alamiah sehingga kualitaslah yang diamati bukan kuantitas.

Menurut Jane Richie, penelitian kualitatif ialah usaha untuk menyuguhkan sosial, perspektifnya dalam dunia, baik konsep, perilaku, persepsi bahkan persoalan tentang manusia yang akan diteliti. Defenisi di sini diunkapakan peran penting dari apa yang harus diteliti yaitu konsep, perilaku, persepsi, dan persoalan tentang manusia yang diteliti (Lexi, 2008, p. 6)

Dari definisi ini dapat dikatakan bahwa penilitian kualitatif adalah penelitian untuk memahami fenomena baik tingkah laku, sikap dll.

Teknik pengumpulan data adalah metode atau cara yang dilakukan peneliti untuk dapat digunakan untuk mengumpulkan data penelitian agar menghasilakan data yang relevan. Menurut Supardi (2006, p. 88) metode observasi ialah metode pengumpulannya dilakukan dengan cara mengamati serta mencatat sistematik gejala gejala yang diselidiki.

Dalam hal ini peneliti pengumpulan data dengan sistem wawancara dengan siswa, guru, dan kepala sekolah. Serta mengikutsertakan siswa SD Negeri Kemirirejo 1 untuk tampil dalam dongeng pagi, lomba lomba yang diadakan oleh Perpustakaan Gita Pustaka SD Negeri Kemirirejo 1 Magelang yang bekerja sama dengan Perpusda Kota Magelang.

\section{HASIL DAN PEMBAHASAN}

\section{Penelitian}

Pendiskripsian Tempat, Subyek, dan Objek

Penelitian ini dilakukan guna memperoleh informasi dalam hal Upaya Guru Meningkatkan
Budaya Literasi Minat Baca Open Reading Garden" siswa Kelas IVA SD Negeri Kemirirejo 1 Magelang. Rincian hasil pendataan yang didapat diambil dari lapangan melalui observasi, wawancara dan dokumentasi

\section{Profil Tempat Penelitian}

Lokasi penelitian berada di sekolah SD Negeri Kemirirejo 1 Magelang yang berada di pusat Kota Magelang, beralamat di Jalan Tentara Pelajar No 110B Magelang, Kecamatan Magelang Tengah.

Data Siswa SD Negeri Kemirirejo 1 Magelang

\begin{tabular}{|c|c|c|c|}
\hline KELAS & LAKI - LAKI & PEREMPUAN & JUMLAH \\
\hline $1 \mathrm{~A}$ & 16 & 12 & 28 \\
\hline $1 \mathrm{~B}$ & 15 & 12 & 27 \\
\hline $2 \mathrm{~A}$ & 12 & 15 & 27 \\
\hline $2 \mathrm{~B}$ & 13 & 14 & 27 \\
\hline 3A & 13 & 14 & 27 \\
\hline 3B & 15 & 12 & 27 \\
\hline 4A & 13 & 19 & 32 \\
\hline 4B & 15 & 17 & 32 \\
\hline 5A & 16 & 17 & 33 \\
\hline 5B & 19 & 14 & 33 \\
\hline 6A & 16 & 12 & 28 \\
\hline 6B & 15 & 12 & 28 \\
\hline JUMLAH & $\mathbf{1 7 8}$ & $\mathbf{1 7 0}$ & $\mathbf{3 4 8}$ \\
\hline
\end{tabular}

Sumber : Data diambil dari Data Dapodik Dokumen Pribadi Sekolah

\section{Jumlah Guru Kelas Dan Guru Mata Pelajaran}

Guru kelas I- VI sebanyak XII orang, Kepala Sekolah I orang, Guru Bahasa Inggris I orang, Guru Agama Katolik I orang, Guru Agama Kristen I orang, Guru Agama Islam II orang, Tata Usaha II orang, Tenaga Pustakawan I orang, Guru Pjok II orang, Tukang Kebun II orang, total sebanyak XXV orang.

\section{Deskripsi Subjek Penelitian}

Subjek penelitian ini yaitu Guru Kelas IVA, Siswa Kelas IVA, dan Kepala Sekolah. Setelah melalui observasi dan wawancara ternyata informasi dapat terpenuhi. Data diperoleh dari dokumen dapodik pribadi sekolah, keseriusan belajar dalam kelas, serta hasil wawancara yang peneliti terhadap Guru dan Kepala Sekolah melalui wawancara. Dan obsevasi dilakukan terhadap Siswa Kelas IVA baik di dalam 
kelas maupun di luar kelas. Dari gurulah informasi terkait dan pokok alam pemberian informasi.

\section{Pendiskripsian Data Hasil Penelitian}

Upaya yang di Lakukan Guru Kelas Agar Dapat Meningkatkan Minat Baca dalam Pembelajaran

Mendorong siswa untuk belajar medongeng atau bercerita mengenai hal yang dibacanya. Berdasarkan penilitian saat proses pelajaran guru sering meminta siswa untuk maju kedepan untuk menceritakan kembali buku yang sudah dibaca, sama dengan hasil wawancara yang sudah dilakukan

Hasil wawancara peneliti dengan Prima, Vano, Raya sebagai berikut:

Peneliti : Pernahkah ketika pelajaran gurumu meminta untuk bercerita kedepan kelas?

Prima : Pernah, bercerita tentang liburan ketika hari minggu (Kamis 4 Maret 2019)

Vano : Pernah, bercerita tentang saudagar dengan sapi dan keledainya (Kamis 4 April 2019)

Raya : Pernah, bercerita tentang kura kura yang sombong (Kamis 4 April 2019)

Dengan demikian hasil wawancara, rata rata siswa sering bercerita setelah membaca, dan hasil wawancara terhadap siswa semakin diperjelas dengan hasil wawancara dengan guru kelas IV A selaku wali kelas kelas IV A. ( Kamis 4 April 2019)

Peneliti : Bagaimana ibu bisa memotifikasi siswa untuk dapat bercerita? Guru Kelas IVA : Saya meminta anak untuk mengambil tema atau hal yang ingin mereka lakukan dan setelah itu mereka harus menceritakan kembali di depan kelas.

Dengan demikian hasil menunjukkan bahwa guru memberikan motifasi agar bercerita dengan memberikan tugas kegiatan liburan hari minggu, ketika masuk siswa untuk bercerita.

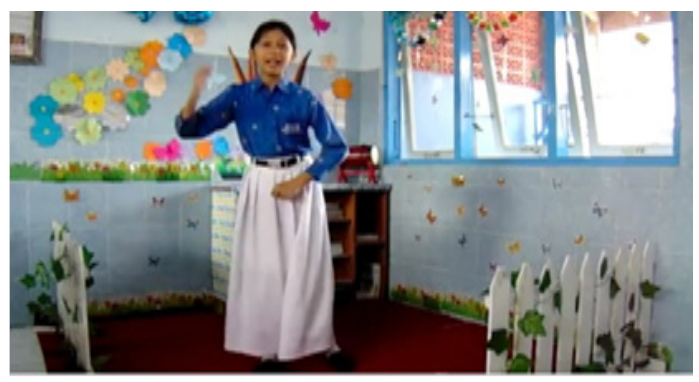

Gambar: Menunjukkan siswa sedang bercerita tentang buku yang sudah dibaca, dan diceritakan didepan kelas.

Bersarkan hasil wawancara terhadap siswa yang diminta untuk bercerita di depan kelas berarti sudah menunjukkan keberhasilan dengan hasil obsrvasi pada Selasa 23 April 2019 dan menceritakan kembali saat dongeng pagi Selasa 7 Mei 20

\section{a. Sistem Tukar Hadiah}

Biasanya dilakukan dengan teman terdekat atau sebangku, dan buku yang biasa ditukar adalah buku pelajaran, atau ketika berkunjung diperpustakaan bertukar dengan teman dengan buku yang sedang di bacanya.

Hasil wawancara sebagai berikut :

Peneliti : Sudah pernahkah kamu saling bertukar buku bacaan baik dengan teman atau sahabatmu? Ruly :Pernah waktu itu bertukar buku LKS ( Senin 8 Juli 2019)

Risky : Pernah juga saat buku bahasa indonesia ( Senin 8 Juli 2019)

Dari wawancara ini dapat disimpulkan tidak hanya buku cerita namun buku pelajaran juga sering menjadi bahan untuk bertukar, dan menjadi bahan cerita.

Peneliti : Bagaimana, apakah kamu menyukai buku yang dipinjam dari temanmu?

Ruly : Iya saya menyukai ( Senin 8 Juli 2019)

Risky : : lya saya juga suka ( Senin 8 Juli 2019)

Dapat disimpulkan bahwa buku yang dipinjam dari temanya sangat bagus untuk dibaca.

Pernyataan ini diperjelas melalui hasil wawancara terhadap guru kelas IVA beliau mengatakan jika di sekolah mengadakan budaya literasi 
dengan membaca 15 menit setiap hari sebelum pelajaran, selain himbauan dari pemerintah budaya literasi ini juga menjadi suatu program sekolah SD Negeri Kemirirejo 1 Magelang. Untuk menunjang budaya literasi saya sebagai guru kelas menyarankan untuk mencari buku bacaan di perpustakaan, meskipun banyak yang menyukai dan semangat namun masih juga yang tidak memiliki semangat untuk tidak membaca.

Peneliti : Apakah siswa diminta untuk membaca buku di sekolah?

Guru : Sebelum dimulai pelajaran diadakan membca 15 menit sering disebut dengan literasi 15 menit, budaya membaca 15 menit ini dianjurkan agar siswa belajar untuk membaca, ketika saya meminta untuk mencari buku diperpustakaan ada siswa yang menyukai namun ada juga yang tidak menyukai.

Berdasarkan hasil wawancara di atas dapat disimpulkan bahwa budaya literasi dengan membaca selama 15 menit merupakan cara untuk dapat meningkatkan minat baca siswa terhadap membaca.

\section{b. Membeli Buku Yang Diminati Siswa}

Setelah melalui pemgamatan dari hasil wawancara sama seperti dilakukan oleh siswa Prima, Vano, Raya tentang hal buku bacaan apa saja yang dibaca selain buku tentang buku pelajaran. Mereka membeli buku seperti majalah anak anak seperti kisd, bobo,mombi, komik dll. Wawancara sebagai berikut :

Peneliti : Bacaan apa sajakah yang banyak diminati oleh siswa selain buku pelajaran?

Prima : Buku tentang legenda seperti terjadinya Gunung Tangkuban Perahu ( Kamis 4 April 2019) Vano: Majalah Bobo dan komik (Kamis 4 April 2019) Peniliti: Buku mana yang paling kamu suka? Prima: Buku Dongeng ( Kamis 4 April 2019)

Vano : Majalah Bobo ( Kamis 4 April 2019)

Raya : Komik( Kamis 4 April )

Dari hasil wawancara tersebut apat ditarik kesimpulan bahwa selain buku pelajaran siswa juga membaca buku sesuai dengan keinginan mereka masing masing dan hampir $90 \%$ lebih suka membaca buku fiksi.

Hasil wawancara agar lebih jelas dengan hasil wawancara yang di lakukan terhadap Guru Kelas IV A

Peneliti : Apakah ibu sering memberikan buku yang disukai siswa?

Guru : Iya sebagai hadiah akan prestasi yang dicapai ( Selasa 23 Juli 2019)

Sesuai hasil wawancara di atas dapat disimpulkan bahwa guru memberikan keterangan, jika beliau sering memberi pujian berupa hadiah seperti buku agar dapat menarik minat baca anak. ( Selasa 23 Juli 2019)

Selain itu hasil wawancara juga memberikan keterangan bahwa buku yang banyak diminati siswa kelas IVA ialah buku cerita yang menjadikan daya tarik. Hasil ini diperoleh dari data pada hari Selasa tanggal 23 April 2019 seluruh siswa kelas IVA hanya membeli bacaan yang mereka mina.

\section{c. Memberikan Waktu untuk Membaca}

Dengan memberikan jadwal kunjung keperputakaan sekolah yang selalu terbuka selama hari efektif kegiatan belajar mengajar.

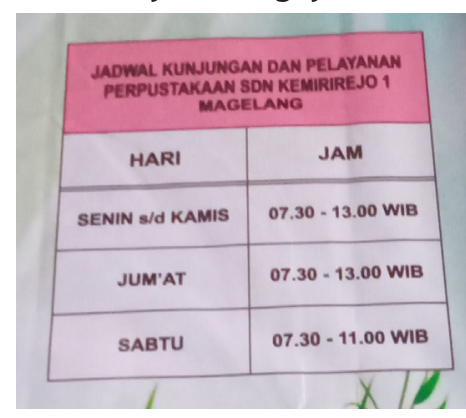

Banyak hal yang dilakukan guru untuk menambah minat baca terhadap siswa. Terutama kelas IVA SD Negeri Kemirirejo 1 Magelang. Diantaranya dengan melakukan kegiatan Lietrasi 15 menit, pemberian hadiah, mendorong siswa untuk memilih buku bacaan yang mereka suka, tukar menukar buku, bahkan menyediakan waktu untuk 
membaca. Bahkan guru sudah mendorong siswa untuk berkunjung keperpustakaan.

\section{E. PENUTUP}

\section{Simpulan}

Perpustakaan Gita Pustaka SD Negeri Kemirirejo 1 Magelang telah menerapkan budaya literasi dengan beberapa inovasi dan beberapa program. Sehingga pemberdayaan budaya literasi open reading garden dapat memberikan nilai postif baik siswa, pendidik, bahkan masyarakat sekitar bahkan mampu meningkatkan minat baca secara optimal. Karena kegiatan ini sudah menjadi program Perpustakaan Gita Pustaka SD Negeri Kemirirejo 1 Magelang, dan kedepanya menjadi kegiatan yang berkelanjutan. Dengan demikian dapat disimpulkan dari pembahasan dan penelitian di atas yaitu : 1) Memberi dorongan terhadap siswa untuk membaca dari apa yang dilihat dan dipahaminya, 2) Memilih bacaan yang menarik minat baca, 3) Bertukar bacaan dengan teman, 4) Memberi hadiah buku untuk meningkatkan minat baca, serta 5) Memberikan waktu membaca di Perpustakaan Gita Pustaka.

Selain itu upaya guru untuk meningkatkan budaya literasi minat baca dengan memberikan tugas di rumah, dan meminta untuk meminjam buku di Perpustakaan Gita Pustaka untuk meminjam dan memahami isi dari yang dibacanya baik buku cerita, majalah, bobo, komik dll

\section{Saran}

Berdasakan kesimpulan di atas maka saran yang diberikan oleh peneliti adalah sebagai berikut : Guru harus terus memberikan dorongan untuk meningkatkan minat baca 1) dorongan agar siswa tetap membaca, 2) terus membeli buku sesuai kesukaan siswa, 3) bertukar bacaan dengan teman, 4) mememberi hadiah buku bacaan, 5) memberi waktu untuk membaca dan tugas tugas di rumah. Siswa kelas IV kebanyakan membaca buku selain buku pelajaran yaitu buku seperti majalah, bobo, komik, buku crita, buku fiksi.

Semoga kedepannya semakin berkembang jadwal rutin literasi open reading garden setiap harinya dan memprogramkan kegiatan sesuai dengan sekolah adiwiyata SD Negeri Kemirirejo 1 Magelang.

\section{DAFTAR PUSTAKA}

Lexi, M. J. (2008). Metodelogi penelitian kuanlitatif. Bandung: Rosda.

Rahim, F. (2007). Pengajaran Membaca Disekolah Dasar. Jakarta: Bumi Aksara.

Sinaga, D. (2005). Mengelola Perpustakaan Sekolah. Bandung: Kibla.

Supardi, M. . (2006). Metodologi Penelitian. Mataram: Yayasan Cerdas Prees.

Zuchdi, D., \& Budiasih. (1997). Pendidikan Bahasa dan sastra Indonesia di Kelas Rendah. Jakarta: Depdikbud. 